\title{
Effect of Ba-dopant on dielectric and energy storage properties of PLZST antiferroelectric ceramics
}

\author{
Ran $\mathrm{Xu}^{*}$, Qingshan Zhu, Jingjing Tian, Yujun Feng, Zhuo Xu*
}

\begin{abstract}

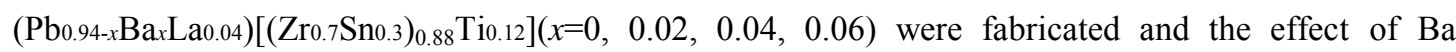
content on the dielectric and energy storage properties was studied. The Ba dopant will weaken the stability of AFE phase and thus lower the transition field. As a result, the recoverable energy density declines while the hysteresis loop will be slimmer. Also, the Curie temperature will decrease with increasing $\mathrm{Ba}$ content but the maximum dielectric constant increases. The temperature dependence of the energy storage properties and dielectric tunability when $x=0.06$ were studied. The stored and recoverable energy density both decline but the efficiency increases with temperature rise. The dielectric tunability is promising when $x=0.06$ at $20^{\circ} \mathrm{C}$ but soon becomes weaker at $80{ }^{\circ} \mathrm{C}$.
\end{abstract}

\section{Keywords}

antiferroelectric ceramics, energy storage, dielectric tunability

\section{Introduction}

Capacitors are key elements in pulsed power technology and power electronics and usually used as energy storage devices [1,2]. For example, in pulsed power systems, enormous electric energy which can be as high as mega joule (MJ) is stored in capacitor banks and then released in a very short duration time to get high pulsed current and power [3]. With the development of pulsed power technology and power electronics, capacitors with higher performance are greatly needed. Thus, as the main part of capacitors, enormous types of dielectrics have been developed and studied.

Among these dielectrics, antiferroelectric has drawn significant attention for their special properties [4-9]. Unlike ferroelectric, the adjacent dipoles in AFEs are anti-parallel and thus there is no 1 
macroscopic spontaneous polarization [10]. When electric field higher than a threshold is applied, the dipoles will be reoriented and the AFE materials will be transformed into FE state. The threshold value is defined as forward transition field $E_{A F E-F E}$. Conversely, when the external field is decreased to a threshold, the induced FE state will return to AFE state. The backward transition electric field is annotated as $E_{F E-A F E}$. Excessive works have been done to bring the AFE materials to the application of capacitors. Among those AFE material systems, La modified Lead Zirconate Titanate Stannate (PLZST) is the most studied one [11-15]. The dielectric and energy storage properties of PLZST ceramics could be modified by composition variation, adding dopants (such as $\mathrm{Ba}$ or $\mathrm{Sr}$ ) or improving preparation technology. For example, Ling Zhang et al. developed $\left(\mathrm{Pb}_{0.858} \mathrm{Ba}_{0.1} \mathrm{La}_{0.02} \mathrm{Y}_{0.008}\right)\left(\mathrm{Zr}_{0.65} \mathrm{Sn}_{0.3} \mathrm{Ti}_{0.05}\right) \mathrm{O}_{3^{-}}$ $\left(\mathrm{Pb}_{0.97} \mathrm{La}_{0.02}\right)\left(\mathrm{Zr}_{0.9} \mathrm{Sn}_{0.05} \mathrm{Ti}_{0.05}\right) \mathrm{O}_{3}$ AFE composite ceramics by Spark Plasma Sintering (SPS) and 6.4 $\mathrm{J} / \mathrm{cm}^{3}$ recoverable energy density could be obtained [16]. Also, Wang et al. studied the dielectric and phase transition properties of Ba-doped PLZST ceramics and found their potential for uncooled heat sensing applications and high-power energy-storage. [9].The Ba-doped PLZST also shows good tunability $[17,18]$. In our former work, the $\mathrm{Pb}_{0.90} \mathrm{La}_{0.04} \mathrm{Ba}_{0.04}\left[\left(\mathrm{Zr}_{0.6} \mathrm{Sn}_{0.4}\right)_{0.85} \mathrm{Ti}_{0.15}\right] \mathrm{O}_{3}$ antiferroelectric ceramics are found with good fatigue resistance under fast charge-discharge cycling [7]. Based on these results, the Ba-doped PLZST ceramics are with great potential for many applications. However, some more detailed conclusions are still needed, such as effects of Ba-dopants on energy storage and dielectrics properties, the temperature dependence of energy storage and tunability of Ba-doped PLZST.

In the present work, the Ba-doped PLZST ceramics were prepared and the effect of Ba-dopant on the dielectric and energy storage properties were studied systematically. Also, it was found that the temperature would influence these properties remarkably. These results may offer some useful conclusions for the development of AFE materials for capacitors or other applications.

\section{Experiments}

$(\mathrm{Pb} 0.94-x \mathrm{Ba} x \mathrm{La} 0.04)\left[\left(\mathrm{Zr}_{0.7 \mathrm{Sn} 0.3}\right)_{0.88} \mathrm{Ti}_{0.12}\right](x=0, \quad 0.02, \quad 0.04,0.06)$ (abbreviated as PLBZST-0, PLBZST-2, PLBZST-4, PLBZST-6, respectively) ceramics were fabricated by solid-state reaction. The raw materials are $\mathrm{Pb}_{3} \mathrm{O}_{4}, \mathrm{La}_{2} \mathrm{O}_{3}, \mathrm{ZrO}_{2}, \mathrm{SnO}_{2}, \mathrm{TiO}_{2}$, and $\mathrm{BaCO}_{3}$ with high purities not less than $99 \%$. They were weighed according to the stoichiometric formula and ball milled for $6 \mathrm{~h}$. Then, the materials 
were calcined at $850{ }^{\circ} \mathrm{C}$ for $2 \mathrm{~h}$ and ball milled again for $6 \mathrm{~h}$. The powders were pressed to disks and sintered at $1260{ }^{\circ} \mathrm{C}$ for $2 \mathrm{~h}$. The sintered disks were printed with sliver electrodes after polished.

The surface of the samples was observed by scanning electron microscopy (SEM, Quanta F250, FEI Quanta, FEI, USA). The curves of polarization versus electric field $(P-E)$ were measured by ferroelectric testing platform (TF analyzer 2000, aixACCT, Germany). The curves of temperature versus dielectric constant $\left(\varepsilon_{r}-T\right)$ and loss tangent $(\tan \delta-T)$ were measured by an LCR meter (Agilent E4980A, Agilent, USA). The ceramics were housed in a stove and could be heated to $300{ }^{\circ} \mathrm{C}$.

\section{Results and discussion}

Fig. 1 shows the SEM images of the obtained ceramics. All the ceramics have no remarkable pores on the surface. However, the grains apparently become smaller with increasing Ba content. In PLBZST-0 2, the average size is about $4 \sim 5 \mu \mathrm{m}$. In PLBZST-4 6, the average size decreases to about $3 \mu \mathrm{m}$. The X-ray diffraction (XRD) patterns are illustrated in Fig. 2. There is no evident impurity peak in the diagrams. Thus, the obtained ceramics are crystalized into single perovskite phase and there is no secondary phase.

The curves of temperature versus dielectric constant $\left(\varepsilon_{r}-T\right)$ and loss tangent $(\tan \delta$-T) with different Ba content are shown in Fig. 3. Apparent peaks are observed in the four $\varepsilon_{r}-T$ curves and they indicate the phase transition from AFE to paraelectric (PE) state. Thus, the temperature which corresponds to the maximum dielectric constant is defined as Curie temperature $T_{c}$ of AFE materials. With increasing Ba content, $T_{c}$ will drop from $148{ }^{\circ} \mathrm{C}$ in PLBZST-0 to $91{ }^{\circ} \mathrm{C}$ in PLBZST-6. However, the maximum dielectric constant shows opposite tendency. It will become higher with increasing Ba content. The maximum relative dielectric constant is 1394 in PLBZST-0 and 3276 in PLBZST-6.

The P-E curves of the ceramics are present in Fig 4. All the ceramics have typical double hysteresis loops, which indicates that they are all AFE materials. Also, the hysteresis loop becomes "slimmer" with increasing Ba content. To evaluate the effect more precisely, the parameters are drawn from the polarization current and listed in Fig. 5(a). With increasing Ba content, both the forward and backward transition fields $\left(E_{A F E-F E}\right.$ and $\left.E_{F E-A F E}\right)$ decrease almost linearly. $E_{A F E-F E}$ declines from 50 $\mathrm{kV} / \mathrm{cm}$ in PLBZST-0 to $31 \mathrm{kV} / \mathrm{cm}$ in PLBZST-6 and $E_{F E-A F E}$ decreases from $34 \mathrm{kV} / \mathrm{cm}$ to $21 \mathrm{kV} / \mathrm{cm}$. The decrease of $E_{A F E-F E}$ reveals that the FE phase is easier to be induced. Thus, Ba content will weaken 
the stability of AFE phase. The width of the hysteresis loop can be evaluated by $\triangle E\left(=E_{A F E-F E}-E_{F E-A F E}\right)$. It decreases from $16 \mathrm{kV} / \mathrm{cm}$ in PLBZST-0 to $9 \mathrm{kV} / \mathrm{cm}$ in PLBZST-6, which indicates that the hysteresis loop becomes "slimmer".

The decreasing stabilization of PLZST could be explained by tolerance factor. As to $\mathrm{ABO}_{3}$ perovskites, the tolerance factor is as follow [6]:

$$
t=\frac{r_{A}+r_{o}}{\sqrt{2}\left(r_{B}+r_{o}\right)}
$$

where $r_{A}, r_{b}$, and $r_{O}$ are the radii of $\mathrm{A}, \mathrm{B}$ site cation, and oxygen anion. The perovskite structure will be stable if $0.9<t<1$. When $t>1$, the FE phase is stabilized and when $t<1$, the AFE phase would be stabilized. $\mathrm{Ba}^{2+}$ has large radius than $\mathrm{Pb}^{2+}$, so $\mathrm{Ba}$ content will increase the tolerance factor. Consequently, the antiferroelectricity will be weakened, which reveals the decrease of $E_{A F E-F E}$.

In addition, the $\mathrm{Ba}$ content will influence the energy storage properties. The energy density could be calculated via the hysteresis loops of the samples. The stored energy density $W_{s t}$ in the charge process and the recoverable energy density $W_{r e}$ in the discharge process could be calculated as:

$$
\begin{aligned}
& W_{s t}=\int_{0}^{P_{\max }} E d P \\
& W_{r e}=-\int_{P_{\max }}^{P_{r}} E d P=\int_{P_{r}}^{P_{\max }} E d P
\end{aligned}
$$

where $P_{\max }$ and $P_{r}$ are maximum and remanent polarization, respectively. $W_{r e}$ is shown as gray area in Fig. 4. Due to the hysteresis loop, $W_{\text {re }}$ will be lower than $W_{s t}$. Thus, only part of stored energy will be released. The energy efficiency $\eta$ can be calculated as:

$$
\eta=\frac{W_{r e}}{W_{s t}}<1
$$

The recoverable energy density $W_{r e}$ of each composition under different electric fields is listed in Fig. 5(b). The maximum $W_{r e}$ is obtained in PLBZST-0 under $59 \mathrm{kV} / \mathrm{cm}$ and is $0.90 \mathrm{~J} / \mathrm{cm}^{3}$. The maximum $W_{r e}$ in PLBZST-2 6 is lower because of the decreasing $E_{F E-A F E}$. The energy efficiency of PLBZST-0 under $59 \mathrm{kV} / \mathrm{cm}$ is $69.9 \%$. That means about $30 \%$ electric energy is wasted and transformed to heat. The energy efficiencies of PLBZST-2 6 (all higher than 72\%) are larger than that of PLBSZT-0 because the hysteresis loop is slimmed by Ba-dopant.

As described in Fig. 3, the phase transition from AFE to PE state will be induced by temperature rise. Thus, the dielectric and energy storage properties will be influenced by temperature greatly. The 
hysteresis loops of PLBZST-6 at different temperatures from $20{ }^{\circ} \mathrm{C}$ to $100{ }^{\circ} \mathrm{C}$ at interval of $10{ }^{\circ} \mathrm{C}$ are measured and illustrated in Fig. 6. Apparently, the temperature will influence the hysteresis loop significantly. As the temperature rises, the polarization decreases and the hysteresis loop becomes "slimmer". Above $80{ }^{\circ} \mathrm{C}$, double hysteresis loops, the typical characteristic of AFE materials, have been very indistinctive. This indicates the tendency of phase transition from AFE to PE state.

The ferroelectric and energy storage parameters at different temperatures are shown in Fig. 7. As illustrated in Fig. 7(a), with increasing temperature, the forward transition field $E_{A F E-F E}$ keeps declining almost linearly. However, the backward one $E_{F E-A F E}$ firstly rises slightly and then almost keeps stable. Thus, the width of hysteresis loop $\Delta E$ will drop, which results in slimmer hysteresis loop. The maximum polarization $P_{\max }$ keeps falling from $25 \mu \mathrm{C} / \mathrm{cm}^{2}$ at $20{ }^{\circ} \mathrm{C}$ to $16 \mu \mathrm{C} / \mathrm{cm}^{2}$ at $100{ }^{\circ} \mathrm{C}$. The decreasing rate is about $36 \%$.

The decrease of $P_{\max }$ will result in the declination of energy density. Due to the both declination of $P_{\max }$ and $E_{\text {AFE-FE }}, W_{\text {st }}$ will keep falling almost linearly from $0.73 \mathrm{~J} / \mathrm{cm}^{3}$ at $20^{\circ} \mathrm{C}$ to $0.44 \mathrm{~J} / \mathrm{cm}^{3}$ at $100^{\circ} \mathrm{C}$ and the decreasing rate is $40 \%$. However, as shown in Fig. 7(a), $E_{F E-A F E}$ almost keeps stable at $20^{\circ} \mathrm{C}$ to $70^{\circ} \mathrm{C}$ and even increases at the beginning. Thus, unlike $W_{\text {st }}$, the recoverable energy density $W_{r e}$ will keep stable at $20^{\circ} \mathrm{C}$ to $40{ }^{\circ} \mathrm{C}$ and then decrease with increasing temperature. From $20^{\circ} \mathrm{C}$ to $30^{\circ} \mathrm{C}, W_{r e}$ rises slightly from $0.53 \mathrm{~J} / \mathrm{cm}^{3}$ to $0.54 \mathrm{~J} / \mathrm{cm}^{3}$, which could be attributed to the increasing $E_{F E-A F E}$ at beginning. From $20^{\circ} \mathrm{C}$ to $100{ }^{\circ} \mathrm{C}, W_{\text {re }}$ drops from $0.53 \mathrm{~J} / \mathrm{cm}^{3}$ to $0.38 \mathrm{~J} / \mathrm{cm}^{3}$ and the decreasing rate is about $28 \%$. Due to the decreasing width $\Delta E, \eta$ will keep rising from $73 \%$ at $20{ }^{\circ} \mathrm{C}$ to $86 \%$ at $100{ }^{\circ} \mathrm{C}$.

The DC-bias characteristic of AFE could also be affected by temperature. The curves of $\varepsilon_{r}$ and $\tan \delta$ versus electric field $\left(\varepsilon_{r}-E\right.$ and $\tan \delta$-E) of PLBZST- 6 at $20{ }^{\circ} \mathrm{C}$ and $80{ }^{\circ} \mathrm{C}$ are shown in Fig. 8 . The curves are almost symmetric and there are four peaks in each curve. Near the transition field, $\varepsilon_{r}$ and $\tan \delta$ will reach maximum. Due to the electric field dependence of $\varepsilon_{r}$, AFEs are good candidates for tunable dielectrics which have potential in tunable microwave devices $[17,18]$. At $20{ }^{\circ} \mathrm{C}$, as shown in Fig. 8(a), under positive electric field, the maximum $\varepsilon_{r}$ is 8000 and under negative electric field, the maximum $\varepsilon_{r}$ is about 8069 . The tiny asymmetry may result from measurement error. The minimum value is 1766 under $48 \mathrm{kV} / \mathrm{cm}$. Consequently, the ratio between maximum and minimum value is about 4.6. Wang et al. studied the dielectric behavior of $\left(\mathrm{Pb}_{0.87} \mathrm{Ba}_{0.08} \mathrm{Sr}_{0.02} \mathrm{La}_{0.02}\right)\left(\mathrm{Zr}_{0.65} \mathrm{Sn}_{0.27} \mathrm{Ti}_{0.08}\right) \mathrm{O}_{3}$ and the ratio is about 2.0 [18]. Also, Wang et al. found the $\left(\mathrm{Pb}_{0.85} \mathrm{Ba}_{0.11} \mathrm{La}_{0.03}\right)\left(\mathrm{Zr}_{0.76} \mathrm{Sn}_{0.20} \mathrm{Ti}_{0.04}\right)$ ceramics have good tunability and the ratio is close to 3.0 [17]. Thus, the obtained PLBZST-6 ceramics show very 
promising tunability. When the temperature increases to $80^{\circ} \mathrm{C}$, as shown in Fig. $8(\mathrm{~b})$, the curves tend to be flat and the peaks become lower, which indicates that the tunability will be weakened by temperature rise. At $80{ }^{\circ} \mathrm{C}$, the ratio between maximum and minimum value is only about 1.8 . Consequently, the temperature will also affect the tunability of AFE materials greatly.

\section{Conclusion}

$(\mathrm{Pb} 0.94-x \mathrm{Ba} \times \mathrm{La} 0.04)\left[(\mathrm{Zr} 0.7 \mathrm{Sn} 0.3)_{0.88} \mathrm{Ti0} .12\right)(x=0,0.02,0.04,0.06)$ were fabricated via traditional solid reaction and the effect of $\mathrm{Ba}$ content on the dielectric and energy storage properties was studied systematically. The stability of AFE phase will be weaken by Ba dopant. Thus, the phase transition field will become lower. The maximum $W_{r e}$ is obtained in PLBZST-0 under $59 \mathrm{kV} / \mathrm{cm}$ and is 0.90 $\mathrm{J} / \mathrm{cm}^{3}$

The temperature will result in declination of energy density but increasing energy efficiency. Also, the obtained ceramics when $x=0.06$ show good tunability at $20^{\circ} \mathrm{C}$.

\section{Acknowledgment}

This work is supported by "111" Project (B14040), the National 973 Project of China under Grant no. 2015CB654602, the National Science Foundation of China (NSAF) under Grant no. U1230116 and International Science \& Technology Cooperation Program of China under Grant no. 2015DFA51100.

\section{Reference}

[1] O. Bouhali, B. Francois, E.M. Berkouk, C. Saudemont, DC link capacitor voltage balancing in a three-phase diode clamped inverter controlled by a direct space vector of line-to-line voltages, IEEE Trans. Power Electron. 22 (5) (2007) 1636-1648.

[2] E.J. Matthews, M. Kristiansen, A.A. Neuber, Capacitor Evaluation for Compact Pulsed Power, IEEE Trans. Plasma Sci. 38 (3) (2010) 500-508.

[3] F. Lassalle, A. Loyen, A. Georges, B. Roques, H. Calamy, C. Mangeant, J.F. Carnbonie, S. Laspalles, D. Cadars, G. Rodriguez, J.M. Delchie, P. Combes, R. Lample, T. Chanconie, J. Saves, Status on the Sphinx machine based on the 1- $\mu$ s LTD technology, IEEE Trans. Plasma Sci. 36 (2) (2008) 370-377.

[4] R. Xu, Z. Xu, Y.J. Feng, X.Y. Wei, J.J. Tian, D. Huang, Polarization of antiferroelectric ceramics for pulse capacitors under transient electric field, J. Appl. Phys. 119 (22) (2016) 224103.

[5] X. Wang, J. Shen, T. Yang, Y. Dong, Y. Liu, High energy-storage performance and dielectric properties of antiferroelectric $\left(\mathrm{Pb}_{0.97} \mathrm{La}_{0.02}\right)\left(\mathrm{Zr}_{0.5} \mathrm{Sn}_{0.5-x} \mathrm{Ti}_{x}\right) \mathrm{O}_{3}$ ceramic, J. Alloys. Compd. 655 (2016) 309-313.

[6] R. Xu, Z. Xu, Y.J. Feng, J.J. Tian, D. Huang, Energy storage and release properties of Sr-doped $(\mathrm{Pb}, \mathrm{La})(\mathrm{Zr}, \mathrm{Sn}, \mathrm{Ti}) \mathrm{O}_{3}$ antiferroelectric ceramics, Ceram. Int. 42 (11) (2016) 12875-12879. 
[7] R. Xu, Z. Xu, Y. Feng, H. He, J. Tian, K. Yu, Fatigue resistance of $\mathrm{Pb}_{0.90} \mathrm{La}_{0.04} \mathrm{Ba}_{0.04}\left[\left(\mathrm{Zr}_{0.6} \mathrm{Sn}_{0.4}\right)_{0.85} \mathrm{Ti}_{0.15}\right] \mathrm{O}_{3}$ antiferroelectric ceramics under fast charge-discharge cycling, Ceram. Int. 42(7) (2016) 9094-9099.

[8] Q. Zhang, X. Liu, Y. Zhang, X. Song, J. Zhu, I. Baturin, J. Chen, Effect of barium content on dielectric and energy storage properties of (Pb,La,Ba)(Zr,Sn,Ti)O3 ceramics, Ceram. Int. 41 (2) (2015) 3030-3035.

[9] X. Wang, J. Shen, T. Yang, Z. Xiao, Y. Dong, Phase transition and energy storage performance in Ba-doped PLZST antiferroelectric ceramics, J. Mater. Sci.: Mater. Electron. 26 (11) (2015) 9200-9204.

[10] X. Hao, J. Zhai, L.B. Kong, Z. Xu, A comprehensive review on the progress of lead zirconate-based antiferroelectric materials, Prog. Mater Sci. 63 (2014) 1-57.

[11] S. Jiang, L. Zhang, G. Zhang, S. Liu, J. Yi, X. Xiong, Y. Yu, J. He, Y. Zeng, Effect of Zr:Sn ratio in the lead lanthanum zirconate stannate titanate anti-ferroelectric ceramics on energy storage properties, Ceram. Int. 39 (5) (2013) 5571-5575.

[12] H.R. Jo, C.S. Lynch, A high energy density relaxor antiferroelectric pulsed capacitor dielectric, J. Appl. Phys. 119 (2) (2016) 024104.

[13] I.V. Ciuchi, L. Mitoseriu, C. Galassi, G.L. Brennecka, Antiferroelectric to Ferroelectric Crossover and Energy Storage Properties of $\left(\mathrm{Pb}_{1-x} \mathrm{La}_{x}\right)\left(\mathrm{Zr}_{0.90} \mathrm{Ti}_{0.10}\right)_{1-x / 4} \mathrm{O}_{3}(0.02 \leq x \leq 0.04)$ Ceramics, J. Am. Ceram. Soc. 99 (7) (2016) 2382-2387.

[14] B.Y. Huang, Z.X. Lu, Y. Zhang, Y.L. Xie, M. Zeng, Z.B. Yan, J.M. Liu, Antiferroelectric polarization switching and dynamic scaling of energy storage: A Monte Carlo simulation, J. Appl. Phys. 119 (17) (2016) 174103.

[15] Y. Feng, Z. Xu, H. Li, X. Yao, Effect of La modifier on the electric hysteresis of lead zirconate stannate titanate compounds, Ceram. Int. 30 (7) (2004) 1393-1396.

[16] L. Zhang, S.L. Jiang, B.Y. Fan, G.Z. Zhang, Enhanced energy storage performance in $\left(\mathrm{Pb}_{0.858} \mathrm{Ba}_{0.1} \mathrm{La}_{0.02} \mathrm{Y}_{0.008}\right)\left(\mathrm{Zr}_{0.65} \mathrm{Sn}_{0.3} \mathrm{Ti}_{0.05}\right) \mathrm{O}_{3}-\left(\mathrm{Pb}_{0.97} \mathrm{La}_{0.02}\right)\left(\mathrm{Zr}_{0.9} \mathrm{Sn}_{0.05} \mathrm{Ti}_{0.05}\right) \mathrm{O}_{3}$ anti-ferroelectric composite ceramics by Spark Plasma Sintering, J. Alloys. Compd. 622 (2015) 162-165.

[17] J. Wang, T. Yang, K. Wei, G. Li, S. Chen, M.W. Cole, Bi-Tunable Dielectric Constant of Antiferroelectric PZT Ceramics Under DC Electric Field, J. Am. Ceram. Soc. 95 (5) (2012) 1483-1485.

[18] X. Wang, T. Yang, J. Shen, Unique dielectric behavior of $\left(\mathrm{Pb}_{0.87} \mathrm{Ba}_{0.08} \mathrm{Sr}_{0.02} \mathrm{La}_{0.02}\right)\left(\mathrm{Zr}_{0.65} \mathrm{Sn}_{0.27} \mathrm{Ti}_{0.08}\right) \mathrm{O}_{3}$ antiferroelectric ceramics, Mater. Lett. 181 (2016) 220-222. 
Fig. 1. SEM images of PLBZST-0 6 ceramics

Fig. 2. X-ray diffraction (XRD) patterns of PLBZST-0 6 ceramics

Fig. 3. Temperature dependence of $\varepsilon_{r}$ and $\tan \delta$ of PLBZST- $0 \sim 6$ ceramics.

Fig. 4. Hysteresis loops of PLBZST-0 6 ceramics.

Fig. 5. Effect of Ba content on (a) transition fields and (b) recoverable energy density under different electric fields.

Fig. 6. Hysteresis loops of PLBZST-6 ceramics at different temperatures.

Fig. 7. Effect of temperature on (a) ferroelectric properties and (b) energy storage properties of PLBZST-6.

Fig. 8. Temperature dependence of $\varepsilon_{r}-E$ and $\tan \delta$-E at (a) $20^{\circ} \mathrm{C}$ and (b) $80^{\circ} \mathrm{C}$. 


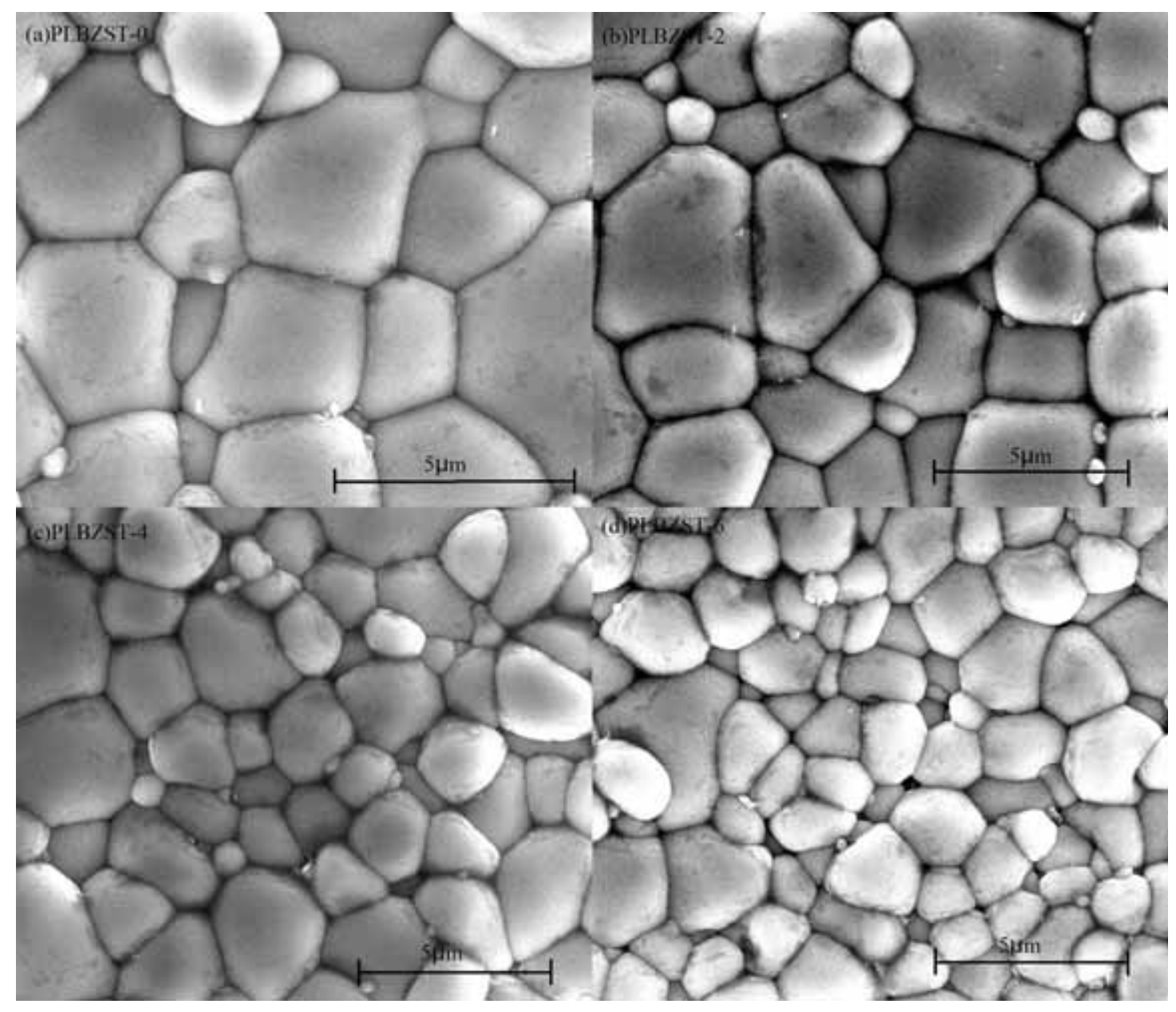




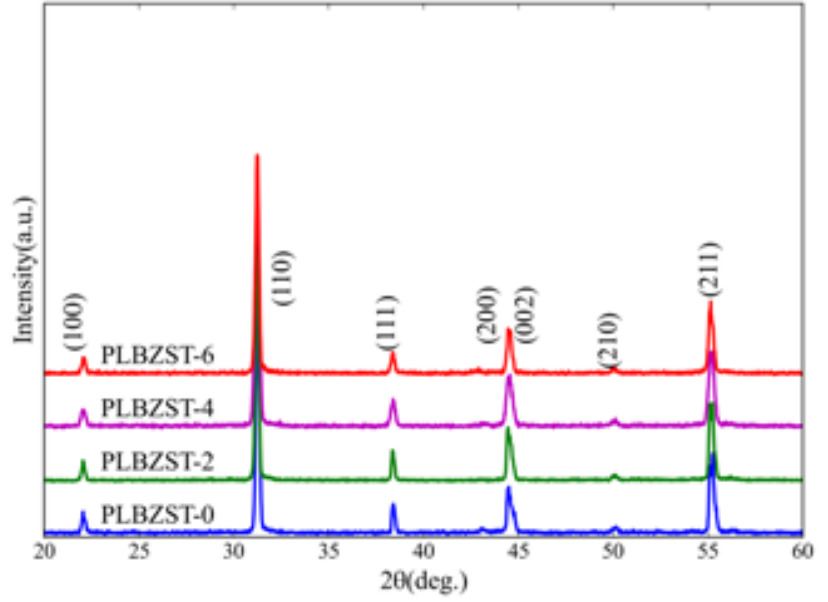




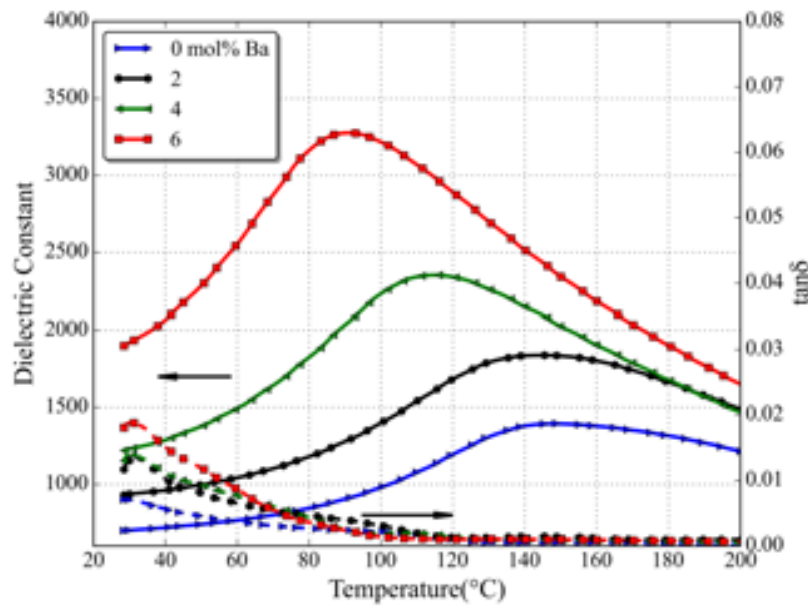



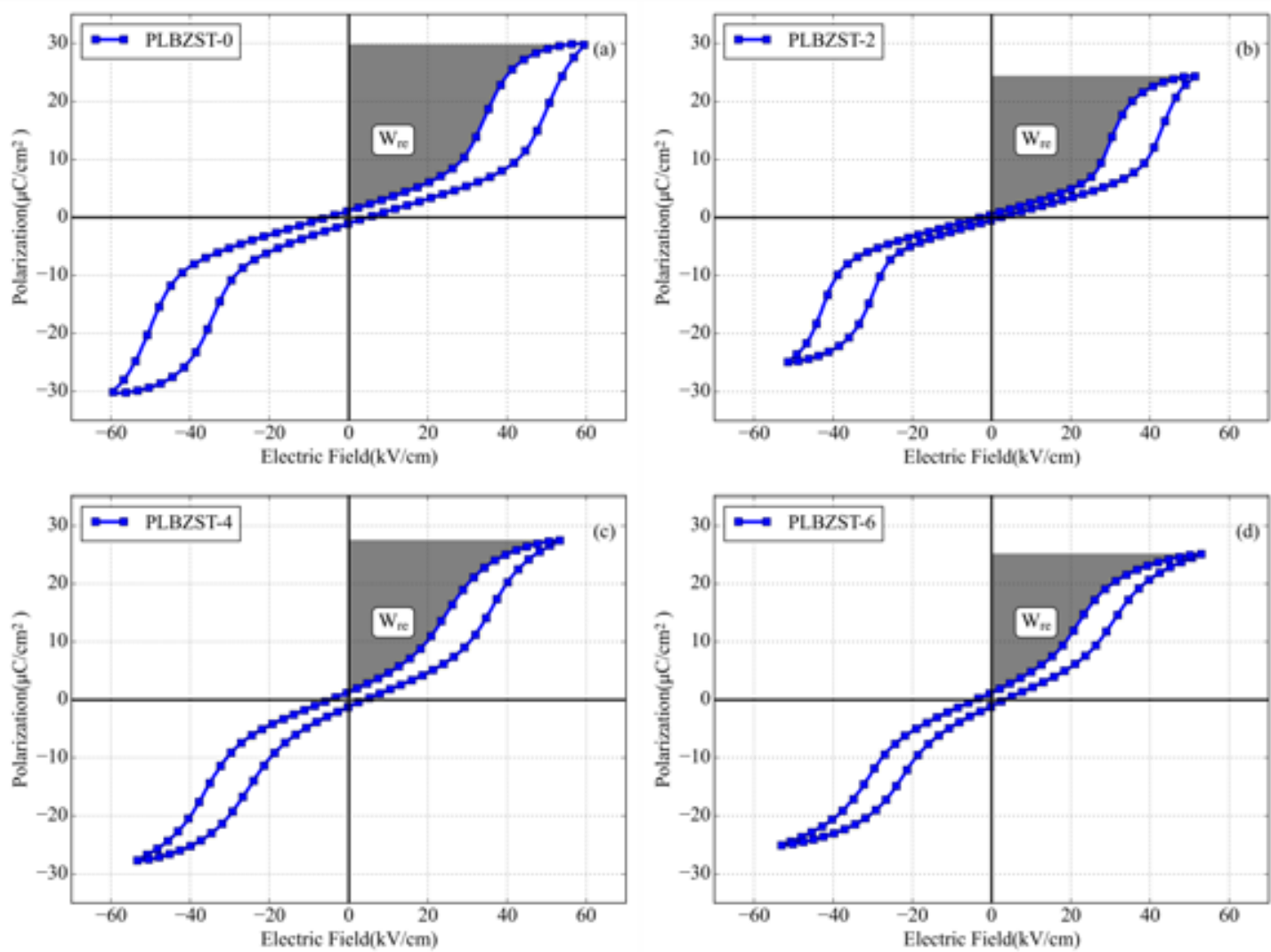

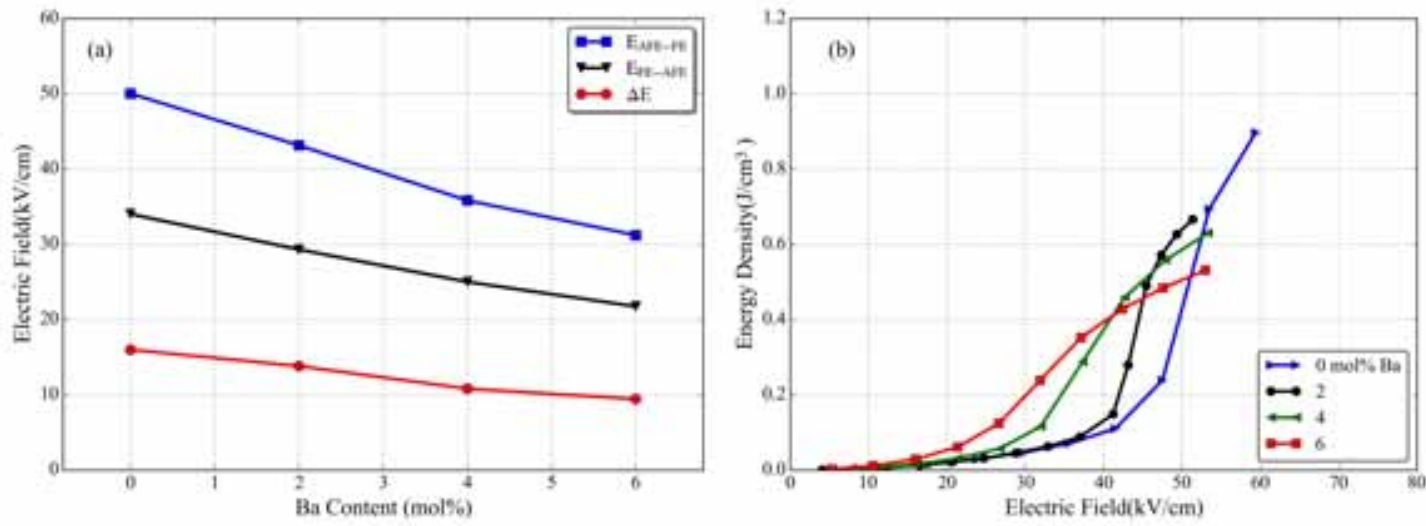


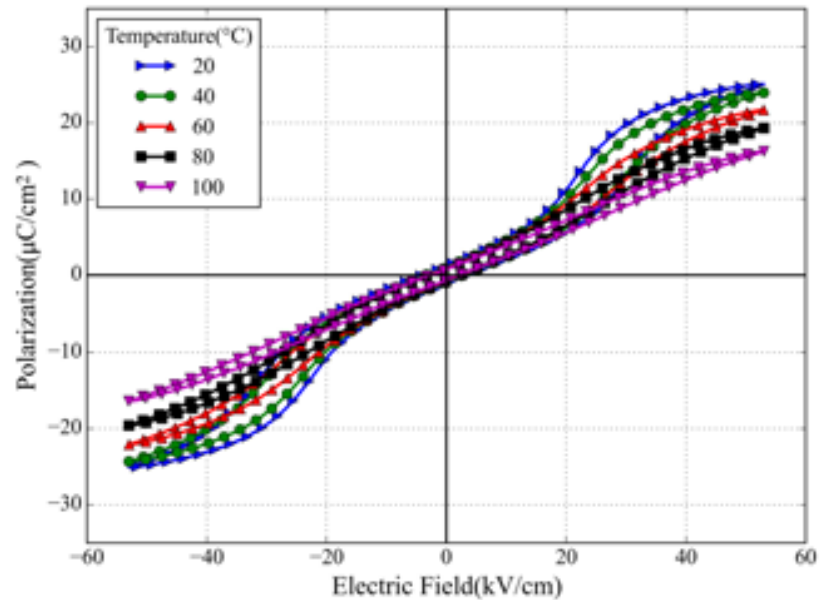



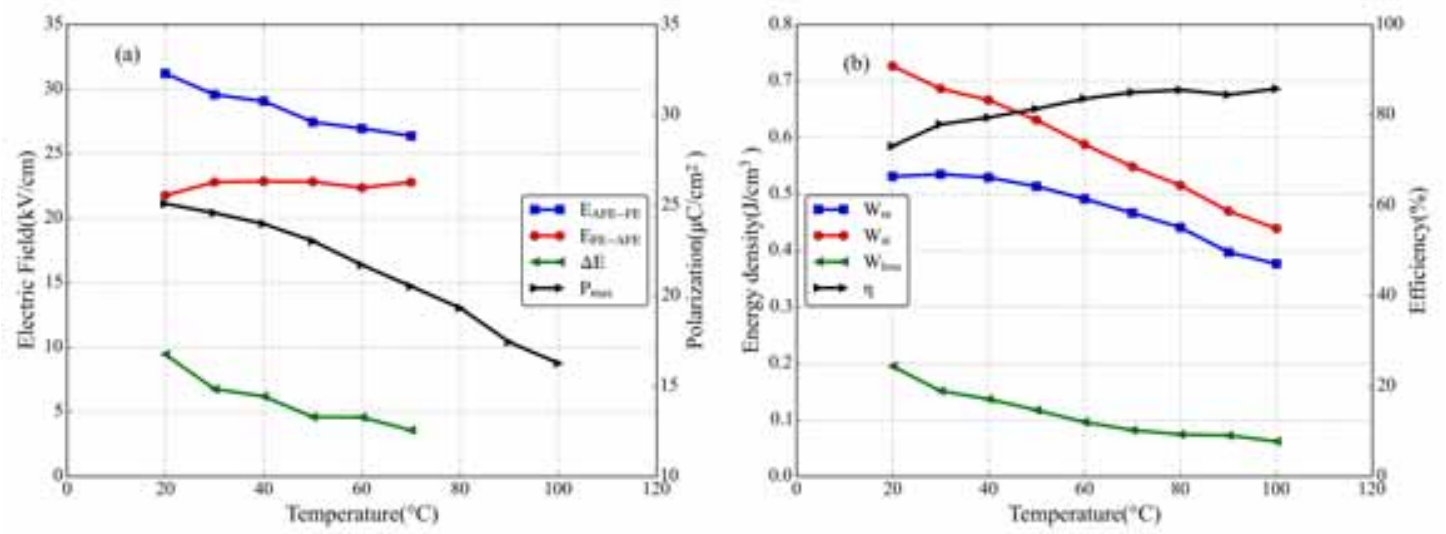

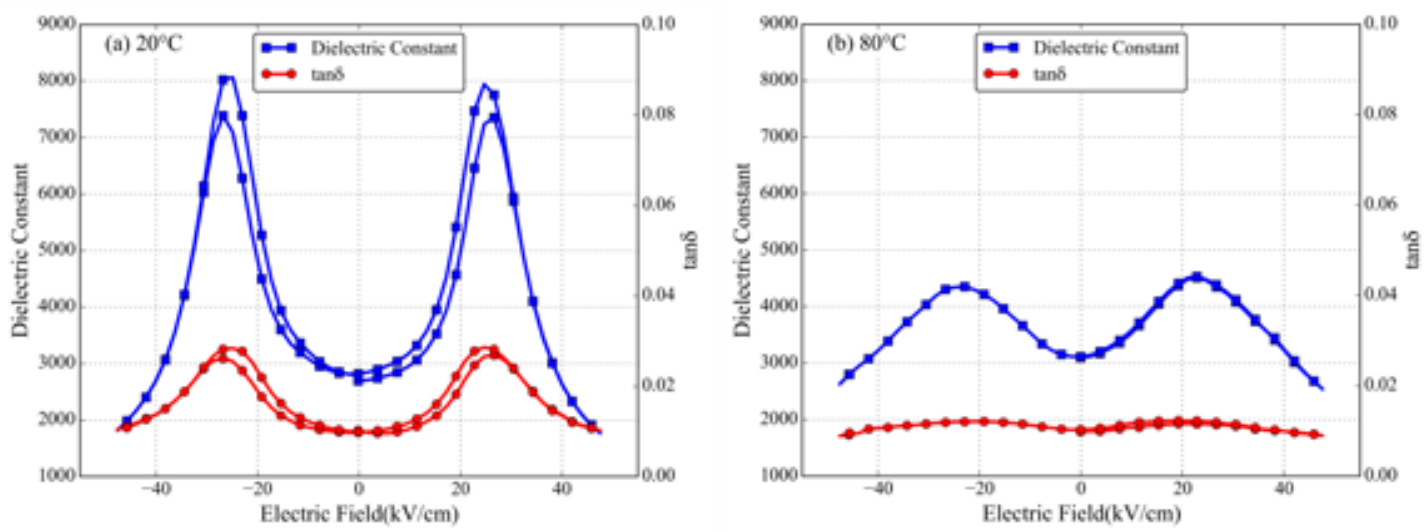